\title{
Optimal Reconfiguration of Power Distribution Systems Based on Symbiotic Organism Search Algorithm
}

\author{
Alexandre Teplaira Boum*, Patrik Roger Ndjependa, Jacquie Ngo Bisse \\ University of Douala, Douala, Cameroon \\ Email: `boumat2002@yahoo.fr, patrikndjependa@yahoo.fr, jackybis@yahoo.com
}

How to cite this paper: Boum, A.T., Ndjependa, P.R. and Bisse, J.N. (2017) Optimal Reconfiguration of Power Distribution Systems Based on Symbiotic Organism Search Algorithm. Journal of Power and Energy Engineering, 5, 1-9. https://doi.org/10.4236/jpee.2017.511001

Received: August 27, 2017

Accepted: November 14, 2017

Published: November 17, 2017

Copyright ( 92017 by authors and Scientific Research Publishing Inc. This work is licensed under the Creative Commons Attribution International License (CC BY 4.0). http://creativecommons.org/licenses/by/4.0/

\begin{abstract}
This paper presents a reconfiguration of electric power distribution network based on the symbiotic organism search algorithm (SOS). The goal here is to come out with an optimal reconfiguration of a power distribution network that minimises the active power losses for a good power flow. This method is applied to IEEE 33 bus and the results show a significant reduction of active power losses. The execution time for this algorithm is found to be smaller compared to other metaheuristic algorithms.
\end{abstract}

\section{Keywords}

Reconfiguration, Algorithm of Symbiotic Search, Metaheuristic Algorithm

\section{Introduction}

The growth of the demand of electrical energy is of a great challenge for the entire society. This calls for optimization of the production, the distribution and the use of electrical energy. The extension of a distribution power network being difficult and costly, it is necessary to optimize the management of the energy in order to ensure the satisfaction of customers, reduce the production cost and increase the income.

There are several technics of optimization of power distribution network. Ahmed Ould Nagi [1] proposed an optimization of power flow in a network using the pareto approach based on genetic algorithm reconfiguration of a network based on the PGSA algorithm (plant growth simulation algorithm). The results obtained with an IEEE 33-bus are presented. M.A. Kashem et al. [3] propose an algorithm that determines the power losses for the different combinations of switches. Bogdan Tomoiaga et al. [4] propose an optimal reconfiguration of 
power distribution network based on genetic algorithm using the flexibility and robustness. Juan $\mathrm{Li}$ [5] proposed an algorithm based on graph theory applied on a network of 200 buses that minimize active and reactive losses during power flow. Francisco Rivas Davalos [6] presented a reconfiguration of power distribution network based on genetic algorithm. P. Subburaj et al. [7] propose a genetic algorithm applied to a 16 buses. It minimizes significantly power losses. This paper presents an approach of minimization of losses using symbiotic organism search algorithm (SOS) to optimize the reconfiguration of the power distribution network. The decision variables are tied to the state of switches. We use the binary code $0(\mathrm{OFF})$ and $1(\mathrm{ON})$ different from Gomes, F. V., et al. [8] who use continuous functions. We apply this algorithm on IEEE 33 bus.

\section{Problem Statement}

Let consider a simple linear network represented bellow Figure 1.

The objective is to minimize the joule losses by a proper reconfiguration of the network. The objective function is therefore:

$$
\min f=\min \left(P_{t, \text { loss }}\right)
$$

with $P_{t, \text { loss }}$, total active losses.

The apparent power carried by a branch, must be less than the maximal apparent power that branch can accept. The amplitude on a nod should be in the accepted range.

These constraints are express by:

$$
\begin{aligned}
S_{i} & \leq S_{i, \text { max }} \\
V_{i, \text { min }} & \leq V_{i} \leq V_{i, \text { max }}
\end{aligned}
$$

The following equations enable us to calculate the power flow.

$$
\begin{gathered}
P_{i+1}=P_{i}-r_{i} \frac{P_{i}^{2}+Q_{i}^{2}}{V_{i}^{2}}-P_{L i+1} \\
Q_{i+1}=Q_{i}-x_{i} \frac{P_{i}^{2}+Q_{i}^{2}}{V_{i}^{2}}-Q_{L i+1} \\
P_{i+1}=P_{i}-r_{i} \frac{P_{i}^{2}+Q_{i}^{2}}{V_{i}^{2}}-P_{L i+1} \\
V_{i+1}^{2}=V_{i}^{2}-2\left(r_{i} P_{i}+x_{i} Q_{i}\right)+\left(r_{i}^{2}+x_{i}^{2}\right) \frac{P_{i}^{2}+Q_{i}^{2}}{V_{i}^{2}}
\end{gathered}
$$

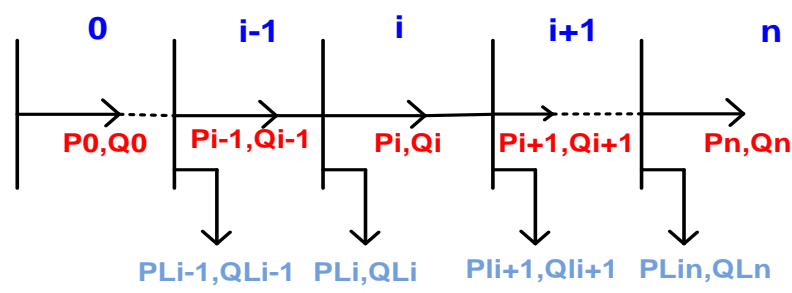

Figure 1. Simple network. 
with:

$P_{i}$ : active power on nod $i$.

$Q_{i}$ : reactive power on node $i$.

$P_{i+1:}$ active power on nod $i+1$.

$Q_{i+1}$ reactive power on node $i+1$.

$r_{i}:$ resistance of branch $i$.

$x_{i}$ : reactance of branch $i$.

$V_{i}$ : real mean value of the voltage on node $i$.

$V_{i+1}$ : real mean value of the voltage on node $i+1$.

$S_{i}$ : apparent power on node $i$.

The total losses are expressed by the relation:

$$
P_{T, \text { loss }}=\sum_{i=0}^{n-1} \frac{P_{i}^{2}+Q_{i}^{2}}{V_{i}^{2}} r_{i}
$$

The goal of the reconfiguration being to minimize the active power losses during the power flow, the problem is stated as follow:

$$
\min \sum_{i=0}^{n-1} \frac{P_{i}^{2}+Q_{i}^{2}}{V_{i}^{2}} r_{i}
$$

Equations (2) and (3) are the constraints.

The reconfiguration hold on the following rules:

- All the load must be fed if not at least most of them.

- The reconfiguration of the network should be radial.

- The network islinear.

If we consider a network of $n$ switches we arrive at the following vector:

$$
X=\left[\begin{array}{lllllll}
x_{0} & x_{1} & x_{2} & x_{3} & x_{4} & \cdots & x_{n-1}
\end{array}\right]
$$

\section{Symbiotic Organism Search Algorithm (SOS)}

The symbiotic organism search algorithm is a new algorithm develop by [9]. It determine the optimal organism that minimizes an objective function. It is ruled by the flow chart Figure 2 .

Mutualism is a social system between the members of a same Professional branch. It is a lasting and complementary relation between two groups of plants, animals or human being.

Commensalism is an association of different species living in such a way that one of them depends on the others without any ham.

Parasitism is linked to predation. In that system, two organisms live together, one feeding himself at the cost of the other.

The detailed flow chart of the symbiotic organism search algorithm is presented at Figure 3.

\section{Description of the Algorithm}

STEP 1:

Initialisation of the ecosystem 


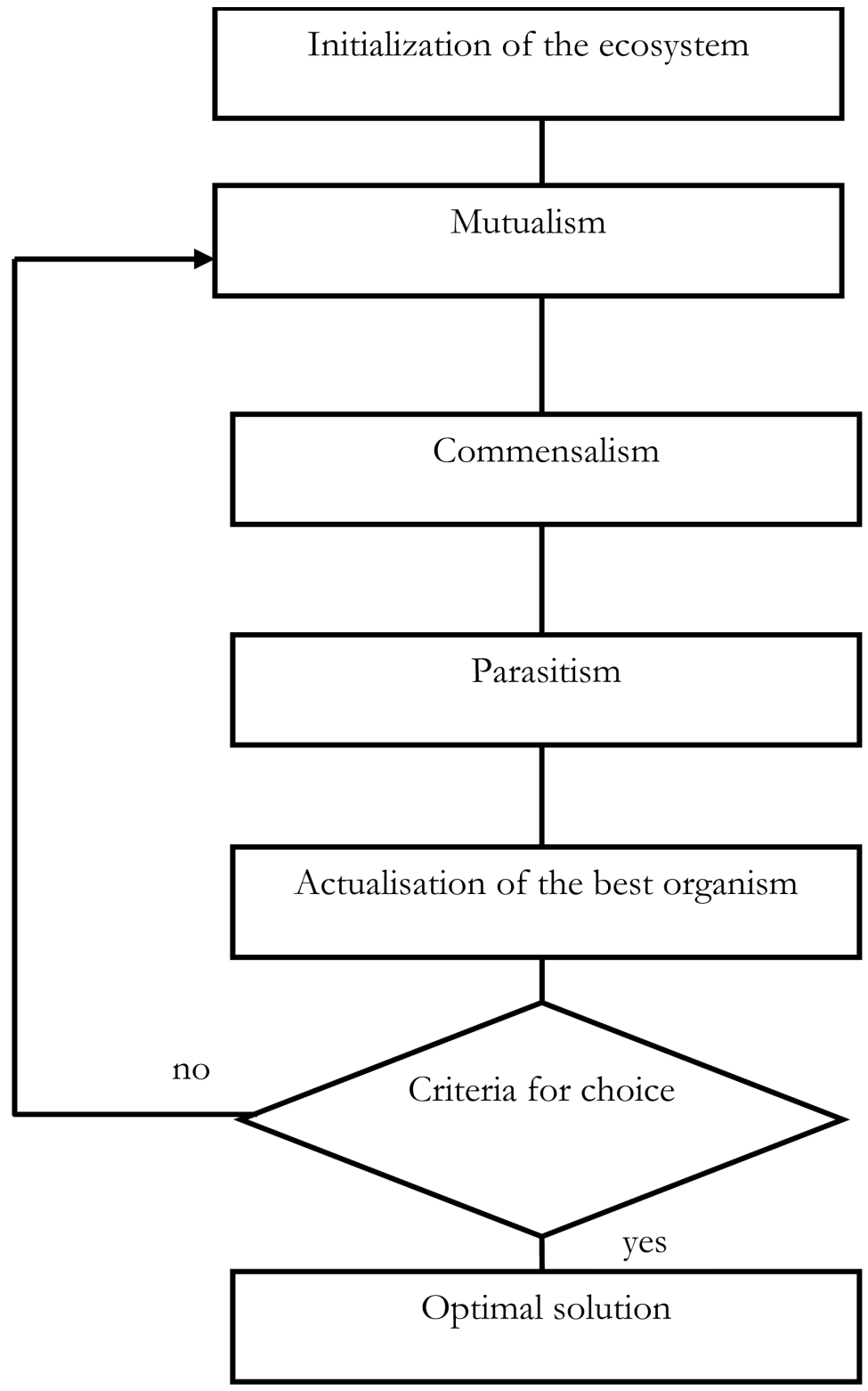

Figure 2. General flow chart for the symbiotic organism search algorithm.

At this level we determine the size of the ecosystem and the initial organism

\section{STEP 2:}

Phase de mutation phase

$Z e$ select at random an organism $X_{j}$ such that. $X_{j} \neq X_{i}$ Determine the mutual vector $\left(X_{i}+X_{j}\right) / 2$. Determine two random number situated between 1 and 2 . Modify the organisms $X_{i}$ and $X_{j}$ taking into account the mutual vector $Z e$ obtain $X_{i n}$ and $X_{\text {jinor }}$ Calculate the value of the fitness function of each new organism and compare them.

STEP 3:

Phase of commensalism

STEP 4:

Phase of parasitism 


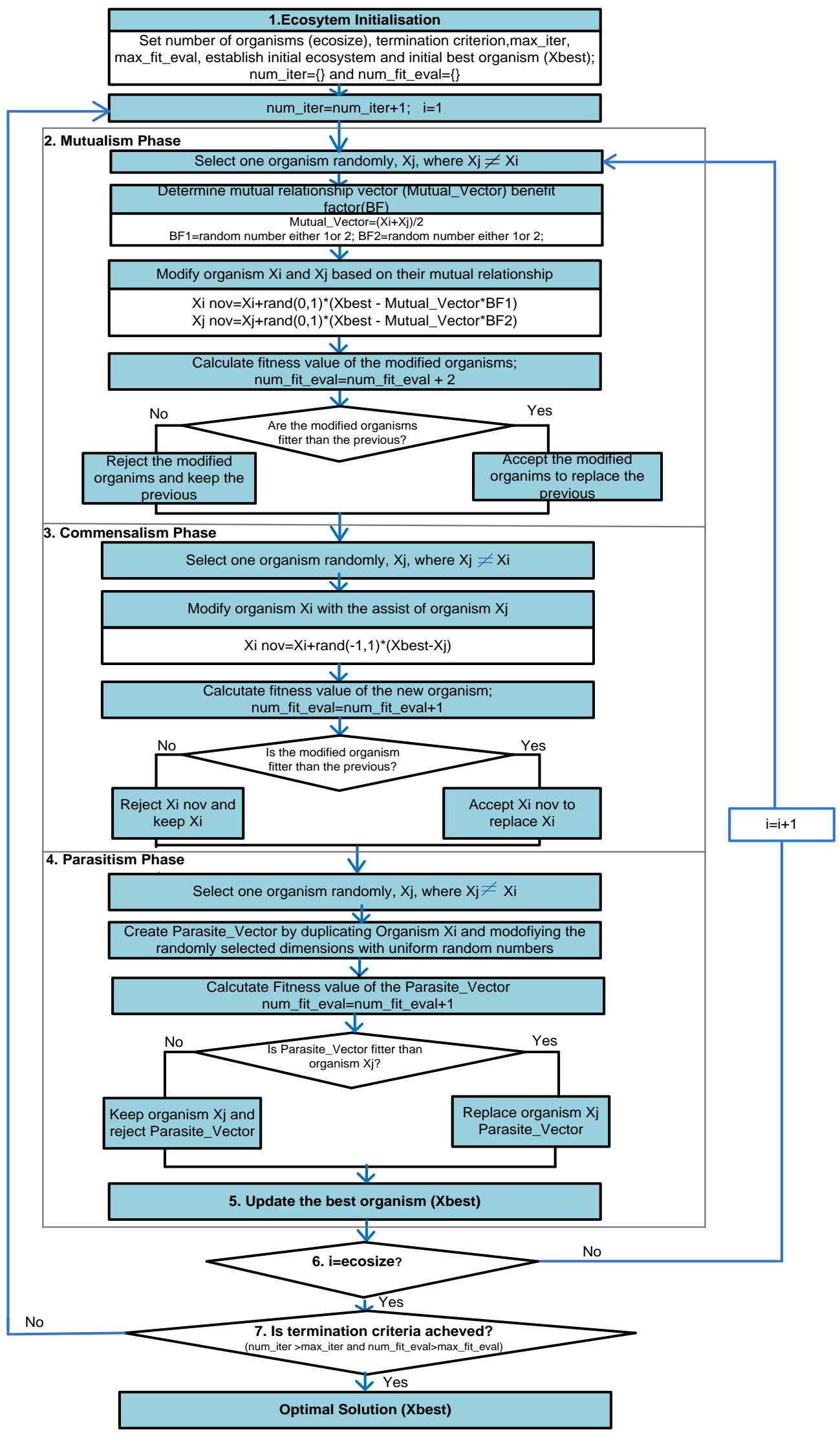

Figure 3. Detailed flow chart of the SOS algorithm [9]. 


\section{Results and Discussion}

The optimization code are written with Matlab. The characteristics of the computer used are: processor of $1.4 \mathrm{GHz}$, memory RAM of 2 Go, OS 64 bite WINDOWS 8.

The result obtained is a 37 elements line matrix. Each element correspond to the state of a switch between two nods. We start by calculating the total lose from the initial configuration. The optimization, give us the best organism witch correspond to the best configuration.

\subsection{Presentation of the Structure}

Figure 4 presents the IEEE 33 bus system.

Initially the state of the switches are: from S1 to S32 "ON" and S33, S35, S36, S37 “OFF".

The rMS of the voltage at nod 0 is $12.66 \mathrm{kV}$ and the active power and reactive powers are respectively $3715 \mathrm{~kW}$ and $2300 \mathrm{kVAr}$.

\subsection{Results}

The characteristics of the network are found in Table 3. The goal is to calculate the active power loss in each branch and apply the optimization algorithm. The implementation is done in the Matlab environment

The initial binary code or organism is Figure 5 .

From S1 to S31 “1" and from S32 to S37 “0".

1) The total loses are: $203,15 \mathrm{~kW}$

The optimal organism which reduce the losses and enable the majority of customers to remain connected is Figure 6.

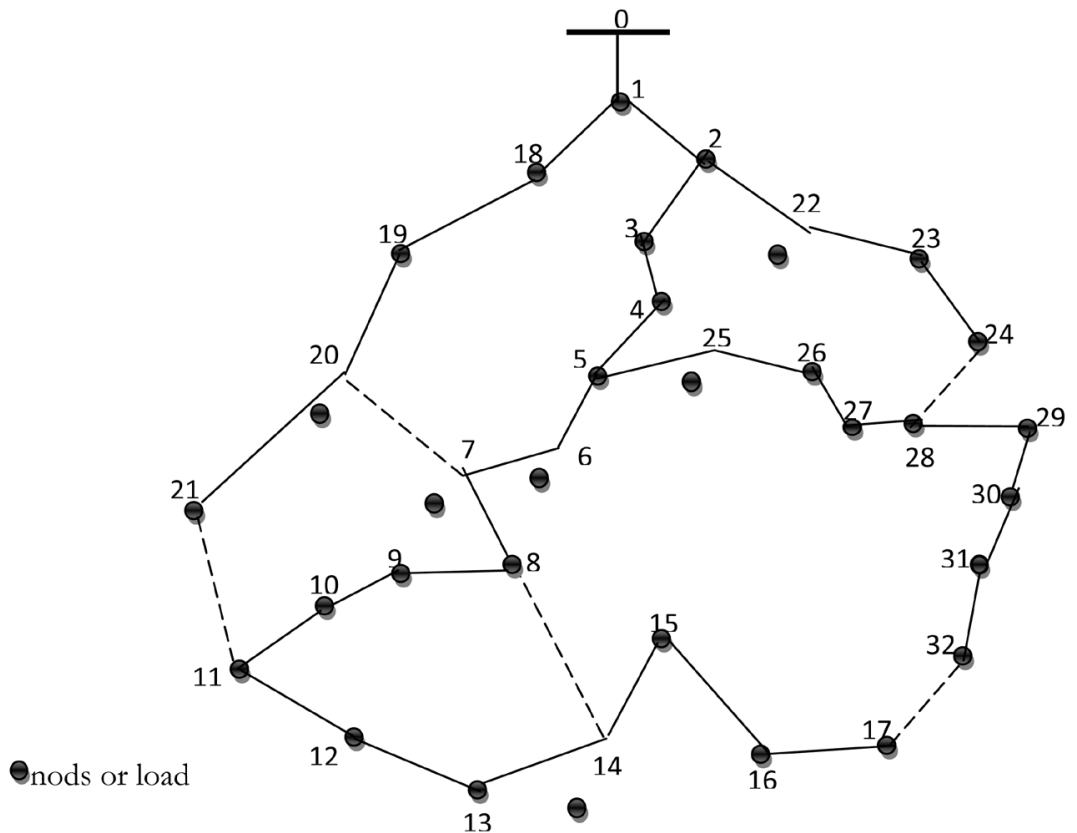

Figure 4. Presentation of the IEEE 33 nods network [2]. 


\section{2) The total losses are: $175,3337 \mathrm{~kW}$}

The summary table is the following Table 1 .

We obtain the following graph Figure 7.

Table 2 shows results obtained by the GA and SOS algorithm with the network characteristic of Table 3.

\subsection{Discussion}

Before the optimization, the open switches are S22, S23, S24, S30, S31, S32, S33, S34, S35, S37 the others are closed. This configuration allows for an active power loss of about $203.15 \mathrm{~kW}$. After the implementation of the SOS algorithm the power loss is reduce to $175.3337 \mathrm{~kW}$ Table 1 . Comparing with genetic algorithm Table 2, after simulations, we can see that the SOS algorithm is more effective

\section{Conclusions}

A novel approach based on symbiotic organism search algorithm has been implemented for the optimization of the distribution of electricity in a power network. The implementation was carried out on an IEEE 33 Bus system. The \begin{tabular}{|l|l|l|l|l|l|l|l|l|l|l|l|l|l|l|l|l|l|l|l|l|l|l|l|l|l|l|l|l|l|l|l|l|l|l|l|l|}
\hline $\mathbf{1}$ & $\mathbf{1}$ & 1 & 1 & 1 & $\mathbf{1}$ & $\mathbf{1}$ & $\mathbf{1}$ & $\mathbf{1}$ & $\mathbf{1}$ & $\mathbf{1}$ & 1 & 1 & 1 & $\mathbf{1}$ & $\mathbf{1}$ & $\mathbf{1}$ & $\mathbf{1}$ & $\mathbf{1}$ & $\mathbf{1}$ & 1 & $\mathbf{1}$ & $\mathbf{1}$ & $\mathbf{1}$ & $\mathbf{1}$ & $\mathbf{1}$ & $\mathbf{1}$ & $\mathbf{1}$ & $\mathbf{1}$ & $\mathbf{1}$ & $\mathbf{1}$ & $\mathbf{0}$ & $\mathbf{0}$ & $\mathbf{0}$ & $\mathbf{0}$ & $\mathbf{0}$ & $\mathbf{0}$ \\
\hline
\end{tabular}

Figure 5. Initialorganism of IEEE 33 bus network.

\begin{tabular}{|l|l|l|l|l|l|l|l|l|l|l|l|l|l|l|l|l|l|l|l|l|l|l|l|l|l|l|l|l|l|l|l|l|l|l|l|l|}
\hline 1 & 1 & 1 & 1 & 1 & 1 & 1 & 1 & 1 & 1 & 1 & 1 & 1 & 1 & 1 & 1 & 1 & 1 & 1 & 1 & 1 & 0 & 0 & 0 & 1 & 1 & 1 & 1 & 1 & 0 & 0 & 0 & 0 & 0 & 0 & 0 & 1 \\
\hline
\end{tabular}

Figure 6. Optimal Organism of the IEEE 33 bus network.

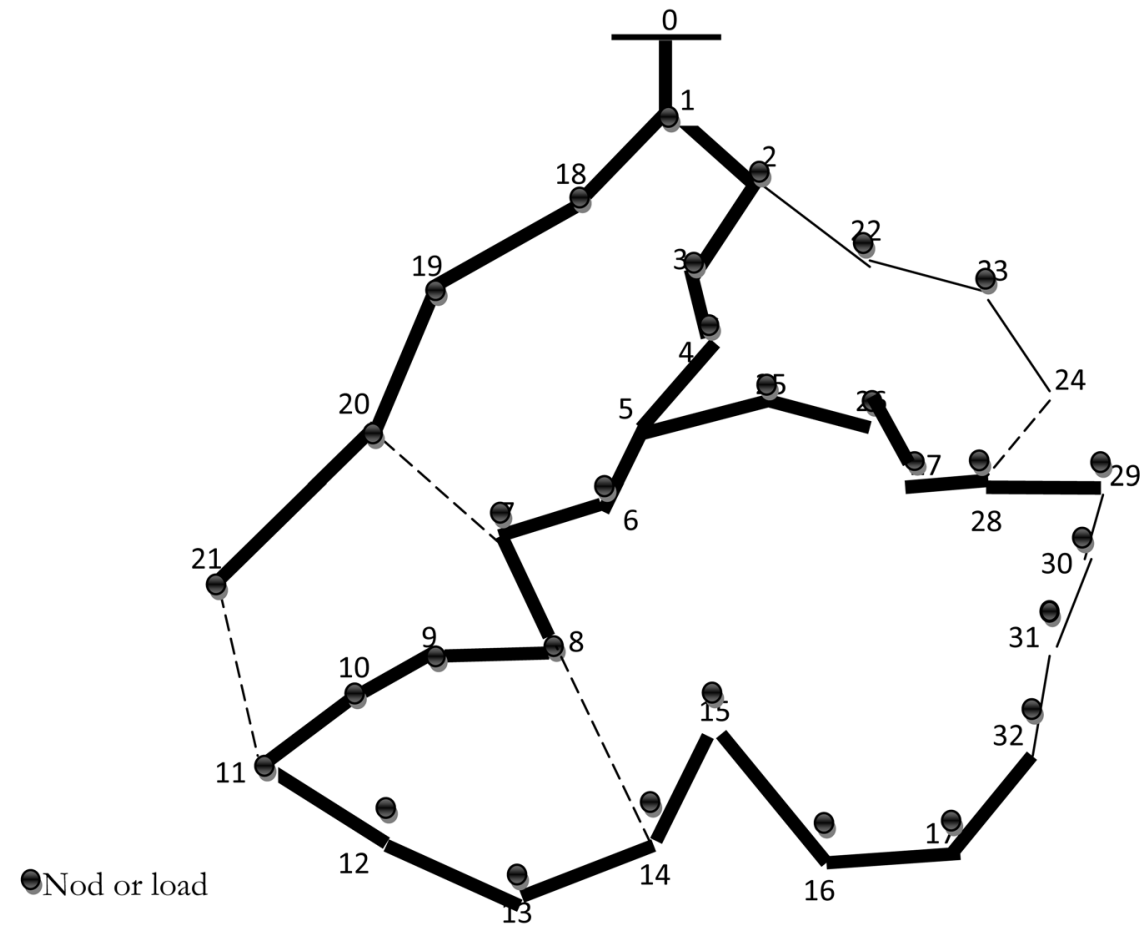

Figure 7. Optimal configuration by SOS algorithm for IEEE 33 nods network. 
Table 1. Reconfiguration of the power network by SOS algorithm.

\begin{tabular}{|c|c|c|c|c|c|}
\hline \multicolumn{3}{|c|}{ Before the reconfiguration } & \multicolumn{3}{|c|}{ After the reconfiguration } \\
\hline \multicolumn{2}{|c|}{ State of the switch } & \multirow{2}{*}{$\begin{array}{c}\begin{array}{c}\text { Total losses } \\
(\mathrm{kW})\end{array} \\
203,15\end{array}$} & \multicolumn{2}{|c|}{ State of the switch } & $\begin{array}{c}\text { Total losses } \\
(\mathrm{kW})\end{array}$ \\
\hline $\begin{array}{l}\text { S32, S33, S34, } \\
\text { S35, S36, S37 }\end{array}$ & OFF & & $\begin{array}{l}\text { S22, S23, S24, S30,S31, } \\
\text { S32, S33, S34, S35, S37 }\end{array}$ & OFF & 175.3337 \\
\hline De S1 à S31 & ON & & Other switches & ON & \\
\hline
\end{tabular}

Table 2. Comparative study between GA and SOS results.

\begin{tabular}{cccc}
\hline Element & Initial state & GA & SOS \\
\hline Open switch & S32, S33, S34, & S15, S25, SS31, S33, S34, S22, S23, S24, S30,S31, S32, \\
& S35, S36, S37 & S35 & S33, S34, S35, S37 \\
Losses $(\mathrm{kW})$ & 203.15 & 194.6427 & 175,3337 \\
Number of itiration & 100 & 100 \\
Execution time (s) & 25.63080 & 0.259030 \\
\hline
\end{tabular}

Table 3. Caracteristics of the test network [2].

\begin{tabular}{|c|c|c|c|c|c|c|c|c|c|c|c|c|c|c|}
\hline $\begin{array}{l}0 \\
0 \\
0 \\
0 \\
0 \\
0\end{array}$ & 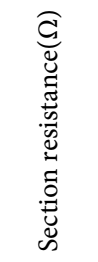 & 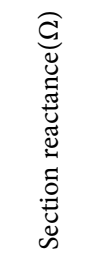 & 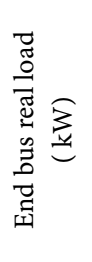 & 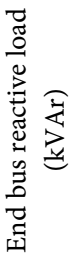 & $\begin{array}{l}0 \\
\vdots \\
0 \\
0 \\
0 \\
0\end{array}$ & 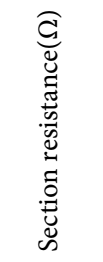 & 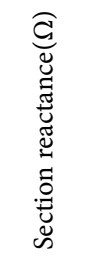 & 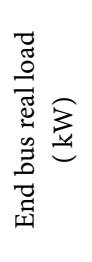 & 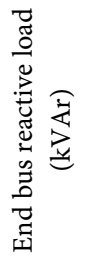 & $\begin{array}{l}n \\
0 \\
0 \\
0 \\
0 \\
0\end{array}$ & 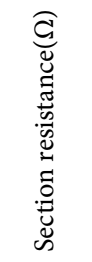 & 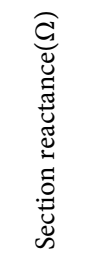 & 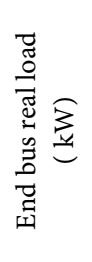 & 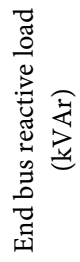 \\
\hline $0-1$ & 0.0922 & 0.0470 & 100 & 60 & $13-14$ & 0.5910 & 0.5260 & 60 & 10 & $25-26$ & 0.2842 & 0.1447 & 60 & 25 \\
\hline $1-2$ & 0.4930 & 0.2511 & 90 & 40 & $14-15$ & 0.7463 & 05450 & 60 & 20 & $26-27$ & 1.0590 & 0.9337 & 60 & 20 \\
\hline $2-3$ & 0.3660 & 0.1864 & 120 & 80 & $15-16$ & 0.2890 & 1.7210 & 90 & 20 & $27-28$ & 0.8042 & 0.7006 & 120 & 70 \\
\hline $3-4$ & 0.3811 & 0.1941 & 60 & 30 & $16-17$ & 0.7320 & 0.5740 & 90 & 40 & $28-29$ & 0.5075 & 0.2585 & 200 & 600 \\
\hline $4-5$ & 0.8190 & 0.7070 & 60 & 20 & $1-18$ & 0.1640 & 0.1565 & 90 & 40 & $29-30$ & 0.9744 & 0.9630 & 150 & 70 \\
\hline $5-6$ & 0.1872 & 0.6188 & 200 & 100 & $18-19$ & 1.5042 & 1.3554 & 90 & 40 & $30-31$ & 0.3105 & 0.3619 & 210 & 100 \\
\hline $6-7$ & 0.7114 & 0.2351 & 200 & 100 & $19-20$ & 0.4095 & 0.4784 & 90 & 40 & $31-32$ & 0.3410 & 0.5302 & 60 & 40 \\
\hline $7-8$ & 1.0300 & 0.7400 & 60 & 20 & $20-21$ & 0.7089 & 0.9373 & 90 & 40 & $7-20$ & 2 & 2 & & \\
\hline $8-9$ & 1.0440 & 0.7400 & 60 & 20 & $2-22$ & 0.4512 & 0.3083 & 90 & 50 & $8-14$ & 2 & 2 & & \\
\hline $9-10$ & 0.1966 & 0.0650 & 45 & 30 & $22-23$ & 0.8980 & 0.7091 & 420 & 200 & $11-21$ & 2 & 2 & & \\
\hline $10-11$ & 0.3744 & 0.1238 & 60 & 35 & $23-24$ & 0.8960 & 0.7011 & 420 & 200 & $17-32$ & 0.5 & 0.5 & & \\
\hline $11-12$ & 1.4680 & 1.1550 & 60 & 35 & $5-25$ & 0.2030 & 0.1034 & 60 & 25 & $24-28$ & 0.5 & 0.5 & & \\
\hline $12-13$ & 0.5416 & 0.7129 & 120 & 80 & & & & & & & & & & \\
\hline
\end{tabular}

simulations led to an optimal reconfiguration that minimizes the active power loss. The comparison of this algorithm with other metaheuristic algorithm such as GA, proves it superiority in losses reduction and short execution time.

In further work, we may consider combination of GA and SOS or another metaheuristic algorithm. 


\section{References}

[1] Nagi, A.O. (2014) Optimization of Power Flow by AG and PSO-TVAC Algorithms. Master Thesis, University of Mohamed Khider Biskra, 116 p.

[2] Wang, C. and Cheng, H.Z. (2008) Optimization of Network Configuration in Large Distribution Systems Using Plant Growth Simulation Algorithm. IEEE Transactions on Power Systems, 23. https://doi.org/10.1109/TPWRS.2007.913293

[3] Muttaqi, K.M., Ganapathy, V., Jasmon, G.B. and Buhari, M. (2000) A Novel Method for Loss Minimization in Distribution Networks. University of Wollongong, Wollongong.

[4] Tomoiagă, B., Chindriş, M., Sumper, A., Sudria-Andreu, A. and Villafafila-Robles, R. (2013) Pareto Optimal Reconfiguration of Power Distribution Systems Using a Genetic Algorithm Based on NSGA-II. Energies, 6, 1439-1455. https://doi.org/10.3390/en6031439

[5] Li, J. (2010) Reconfiguration of Power Networks Based on Graph-Theorical Algorithms. Iowa State University.

[6] Rivas-Davalos, F. (2004) A Genetic Algorithm for Power Distribution System Planning. Brunel University.

[7] Subburaj, P., Rama, K., Ganesan, L. and Venkatesh, P. (2006) Distribution System Reconfiguration for Loss Reduction Using Genetic Algorithm. Journal of Electrical Systems, 2-4.

[8] Gomes, F.V., et al. (2006) A New Distribution System Reconfiguration Approach Using Optimum Power Flow and Sensitivity Analysis for Loss Reduction. IEEE Transactions on Power Systems, 21, 1616-1623.

[9] Cheng, M.-Y. and Prayogo, D. (2014) Symbiotic Organisms Search: A New Metaheuristic Optimization Algorithm. Computers End Structures, 98-112.

\section{Nomenclature}

PGSA: Plant growth simulation algorithm

SOS: Symbiotic organism search algorithm

GA: Genetic algorithm 